\title{
A genomewide linkage analysis of Kawasaki disease: evidence for linkage to chromosome 12
}

\author{
Yoshihiro Onouchi $\cdot$ Mayumi Tamari $\cdot$ Atsushi Takahashi $\cdot$ Tatsuhiko Tsunoda \\ Mayumi Yashiro · Yoshikazu Nakamura · Hiroshi Yanagawa - Keiko Wakui · \\ Yoshimitsu Fukushima · Tomisaku Kawasaki · Yusuke Nakamura • \\ Akira Hata
}

Received: 12 September 2006/ Accepted: 10 November 2006/Published online: 8 December 2006

(C) The Japan Society of Human Genetics and Springer 2006

\begin{abstract}
Kawasaki disease (KD) is an acute systemic vasculitis syndrome that primarily affects infants and young children. The cause of KD is largely unknown, but its higher incidence in the Asian population and increased risk in patients' families suggests the existence of underlying genetic factors. To determine the loci of a susceptibility gene for KD, a genomewide linkage analysis with affected sib pairs was performed on 78 family samples collected from all over Japan. Multipoint linkage analysis using MAPMAKER/SIBS 2.0 identified evidence of linkage on 12q24 [maximum lod score $(\mathrm{MLS})=2.69$ ]. Possible linkage (MLS > 1.0) was also found on $4 \mathrm{q} 35,5 \mathrm{q} 34$, 6q27, 7p15, 8q24, 18q23, 19q13, Xp22, and Xq27. This is the first large-scale study of the genetic suscepti-
\end{abstract}

Y. Onouchi $(\bowtie) \cdot$ A. Hata

Laboratory for Gastrointestinal Diseases,

SNP Research Center, RIKEN,

1-7-22 Suehiro-cho, Tsurumi-ku,

Yokohama, Kanagawa 230-0045, Japan

e-mail: onouchi@src.riken.jp

M. Tamari

Laboratory for Genetics of Allergic Diseases,

SNP Research Center, RIKEN, Yokohama, Japan

A. Takahashi

Laboratory for Statistical Analysis,

SNP Research Center, RIKEN, Tokyo, Japan

T. Tsunoda

Laboratory for Medical Informatics,

SNP Research Center, RIKEN, Yokohama, Japan

M. Yashiro · Y. Nakamura

Department of Public Health, Jichi Medical School,

Minamikawachi, Tochigi, Japan bility to $\mathrm{KD}$, and our results, combined with the accumulated knowledge of the human genome, could greatly promote research on identification of the molecular pathogenesis of KD.

Keywords Kawasaki disease - MCLS .

Complex disorders · Susceptibility genes .

Affected sib pair analysis

\section{Introduction}

Kawasaki disease (KD; MIM300530), also known as mucocutaneous lymph node syndrome (MCLS), was first described in 1967 by the Japanese pediatrician

H. Yanagawa

Saitama Prefectural University,

Koshigaya, Saitama, Japan

K. Wakui · Y. Fukushima

Department of Preventive Medicine,

Shinshu University School of Medicine,

Matsumoto, Japan

T. Kawasaki

Japan Kawasaki Disease Research Center,

Tokyo, Japan

Y. Nakamura

Laboratory of Molecular Medicine,

Human Genome Center, Institute of Medical Science,

The University of Tokyo, Tokyo, Japan

A. Hata

Department of Public Health,

Chiba University Graduate School of Medicine,

Chiba, Japan 
Tomisaku Kawasaki. It is a self-limiting vasculitis syndrome that affects systemic small and medium-sized blood vessels. The symptoms include prolonged fever, nonsuppurative cervical lymphadenitis, and changes in the skin and mucous membranes, such as rash; edema; conjunctival injection; erythema of the oral cavity, lips, and palms; and desquamation of the fingertips (Kawasaki 1967; Burns 2002). Although the incidence has been dramatically lowered by introduction of highdose immunoglobulin therapy, $15-20 \%$ of untreated patients and patients resistant to the therapy develop serious, sometimes life-threatening, cardiac sequelae associated with coronary artery aneurysms (Kato et al. 1975). In Japan, approximately $0.08 \%$ of patients die in the acute phase of the disease, mostly due to cardiac complications (Yanagawa et al. 1998). Furthermore, patients with cardiac sequelae have an increased risk of ischemic heart disease that may lead to myocardial infarction and sudden death (Kato et al. 1996). Currently, $\mathrm{KD}$ is the most common cause of acquired heart disease in childhood in the developed countries. Despite intensive study over more than 35 years, the etiology of the disease has not been clarified. In Japan, 18 nationwide epidemiologic surveys of KD have been carried out biennially from 1970 to the present. These surveys have revealed several important features, such as: (1) unidentified infectious agent(s) appear to play some role, (2) siblings and offspring of KD patients are at higher risk of the disease (Fujita et al. 1989; Uehara et al. 2003), and (3) male predominance of its occurrence (male:female ratio 1.4) and cardiac complications (Yanagawa et al. 1998). These features strongly indicate the existence of genetic factors that determine the susceptibility and severity of $\mathrm{KD}$, in addition to any environmental factors. A possible mechanism of KD onset would be a genetically determined exaggerated immune response triggered by some unknown infection. Thus, identification of genetic factors would greatly facilitate understanding of the disease etiology and pathophysiology. We conducted a nonparametric genome-wide linkage analysis on 78 Japanese affected sib pairs (trios), and several candidate gene loci have been identified.

\section{Materials and methods}

Family samples

Siblings affected with KD were recruited nationwide for this study. All patients were diagnosed by pediatricians according to the criteria established by the Japan Kawasaki Disease Research Committee (http://www.kawasaki-disease.org/diagnostic/index.html). Genomic DNA was extracted from peripheral blood leukocytes or Epstein-Barr-virus-transformed lymphoblastoid cell lines. The Ethical Committee of the Institute of Medical Science, the University of Tokyo and RIKEN approved the study, and all parents gave written informed consent.

\section{Markers and genotyping}

Microsatellite markers from the ABI Linkage Mapping Set MD-10 (Applied Biosystems, Foster City, CA, USA) were used for screening, and genetic mapping information on these markers was obtained from the web site of the Whitehead Institute (http:// www.broad.mit.edu/cgi-bin/contig/phys_map). The allele frequencies and heterozygosity of these markers in the Japanese population have already been described (Ikari et al. 2001). Markers whose heterozygosity has been determined as less than 0.60 in the Japanese population were substituted with alternative ones. To avoid the problem of population stratification, data analyses were conducted with allele frequencies of the markers in founders of the sib pairs. The total number of markers was 399 and the average interval $9.9 \mathrm{cM}$. Polymerase chain reactions (PCRs) for genotyping were performed by the method described previously (Ikari et al. 2001). Pooled PCR products were mixed with GeneScan 500 LIZ Size Standard, and electrophoresis was performed on ABI 3700 capillary DNA sequencers (Applied Biosystems) according to the manufacturer's protocol. Genotyping for each individual was performed using ABI GeneScan 3.5.2 and Genotyper 3.7 software (Applied Biosystems). Inconsistency within families was ruled out using the Checkfam program (http://www.genstat.net/checkfam/ index.cgi?lang $=\mathrm{ja}$ ).

Detailed mapping of a locus in $12 \mathrm{q} 24$

To obtain more information on a locus around the linkage peak in 12q24, we introduced three markers, one already known and two newly identified (Table 1). Primers used for amplification of these markers were as follows: D12S366F 5'-AAATACAGAGAATTG

Table 1 Markers used in high information content mapping

\begin{tabular}{llll}
\hline Markers & Position $(\mathrm{cM})$ & Position $(\mathrm{Mb})$ & Heterozygosity \\
\hline D12S366 & 133.8 & 117.1 & 0.86 \\
12qMS054 & 140.9 & 123.5 & 0.88 \\
12qMS069 & 148.3 & 125.2 & 0.89 \\
\hline
\end{tabular}


Table 2 Record of sample collection

\begin{tabular}{ll}
\hline Type of family samples & \\
Affected sib pair only & 29 \\
Affected sib pair and one parent & 13 \\
Affected sib pair and parents & 23 \\
Affected sib pair and unaffected sib and both parents & 8 \\
Affected sib pair and unaffected sib and one parent & 2 \\
Affected sib trio only & 1 \\
Affected sib trio and one parent & 1 \\
Affected sib trio and both parents & 1 \\
Affected half sib pair & 1 \\
Total & 79 \\
Age & \\
Average age of founders at affection & $3.2^{\mathrm{a}}$ \\
Average age of siblings of founders at affection & $2^{\mathrm{b}}$ \\
Over all average age at affection & 2.5 \\
Gender & \\
Brother/brother pairs & 23 \\
Sister/sister pairs & 15 \\
Mixed pairs & 38 \\
Mixed trios & 3 \\
Total & 79
\end{tabular}

${ }^{a}$ Information was available in 34 patients

b Information was available in 50 patients

GCTCG-3', D12S366R 5'-GGCCGATCACTTCTTG AATC-3', 12qMS054F 5'-CAATCCAGGAACCCAA GTAG-3', 12qMS054R 5'-ACAAGAGACTGCAA CCAGAG-3', 12qMS069F 5'-ATCCAGGTATCCA GGAAAGG-3', 12qMS069R 5'-GAAGGCAGATTT CCCTCAAC- $3^{\prime}$.

Fig. 1 Geographical distribution of pedigrees collected in eight districts of Japan
Table 3 Power calculation of affected sib pair study $(N=78)$

\begin{tabular}{lll}
\hline Locus-specific $\lambda$ s & Lod score & Power \\
\hline 5 & $3.6^{\mathrm{a}}$ & 0.84 \\
& $2.2^{\mathrm{a}}$ & 0.98 \\
3 & 3.6 & 0.54 \\
& 2.2 & 0.85 \\
1.5 & 3.6 & 0.02 \\
& 2.2 & 0.13 \\
\hline
\end{tabular}

a Threshold for significant and suggestive evidence of linkage in genomewide analysis (Lander and Kruglyak 1995)

Statistical analysis

The power of affected sib pair test was calculated using the previously described method (Risch 1990). Both single and multipoint nonparametric linkage (NPL) analyses for all genotype data was performed using the MAPMAKER/SIBS 2.0 program (Kruglyak and Lander 1995). Calculations of the identity by descent (IBD) distribution were conducted every $1.0 \mathrm{cM}$ in the multipoint analyses. In the analyses, family members who had no obvious history of KD were treated as unknown as to whether they were affected. The program was also used to estimate information content. NPL scores and $P$ values were calculated with the GENEHUNTER 2.1 program (Kruglyak et al. 1996); the sex-linked mode of MAPMAKER/SIBS and GENEHUNTER 1.3 program were used for the analysis of chromosome $\mathrm{X}$.

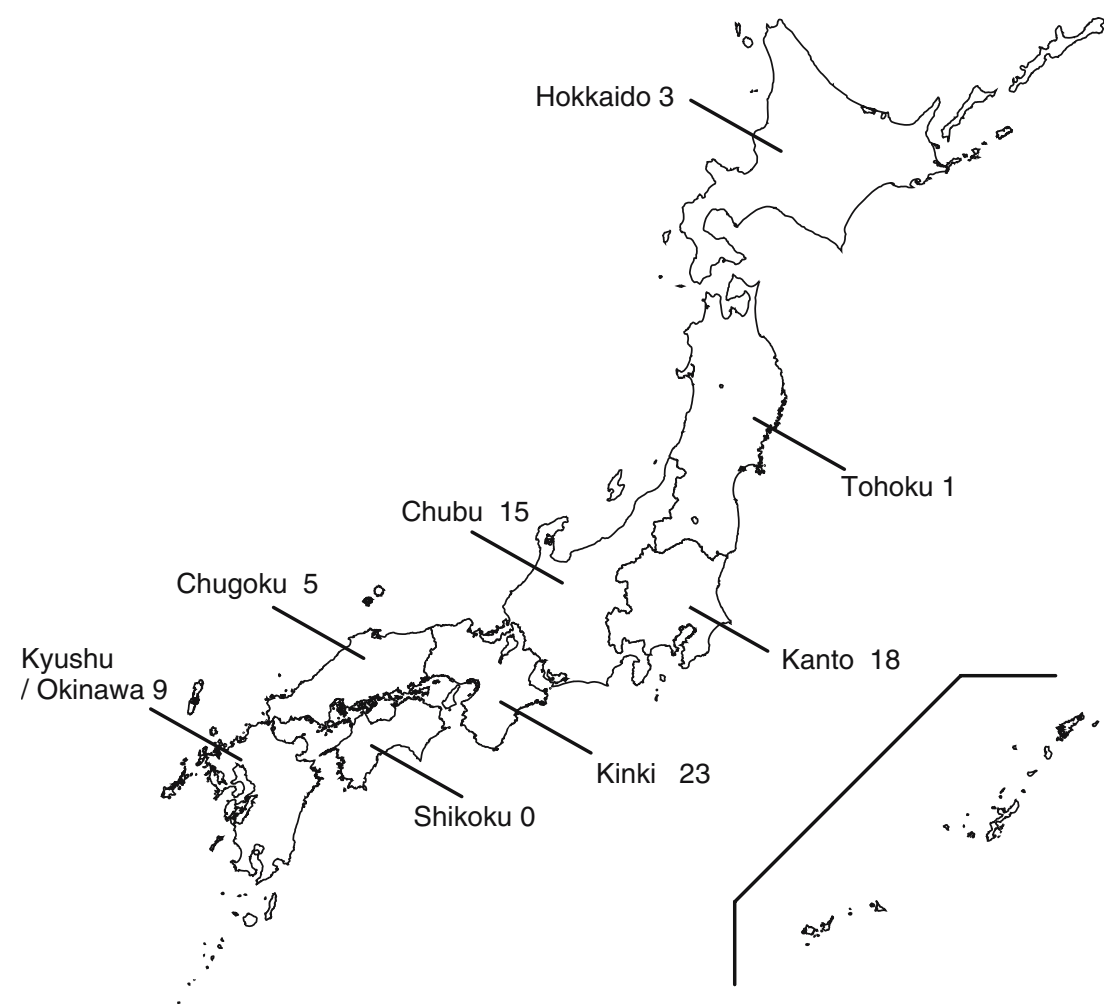



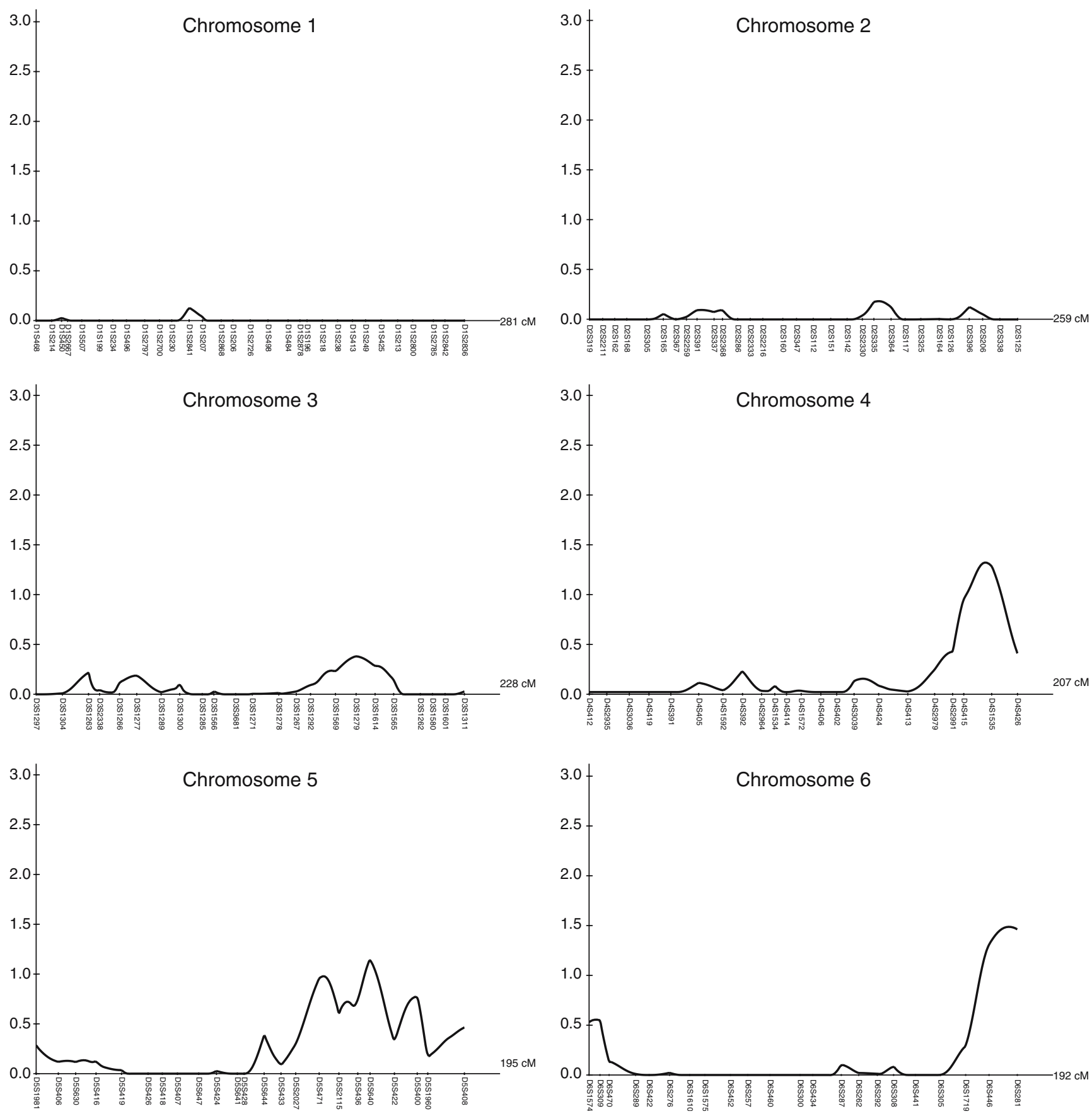

Fig. 2 Genomewide linkage analysis of Kawasaki disease (KD). Genotype data for 78 Japanese KD families were analyzed by MAPMAKER/SIBS. The $Y$ axis indicates the maximum lod

score (MLS) values, and the $X$ axis indicates the relative position of the microsatellite markers in each chromosome. The right side of the $\mathrm{X}$ axis corresponds to the $\mathrm{q}$ terminal of the chromosome

obtained in ten families (Table 2). The geographical distribution of patients recruited in this study as affected sib pairs is displayed in Fig. 1. The result of the power calculation of sib pair analysis is summarized in Table 3. According to this result, detection of suggestive linkage could be expected at loci with $\lambda$ s larger than 3.0 with an acceptable power $(>0.80)$. Average In 48 families, samples of either or both parents were available. Samples from unaffected siblings were also 

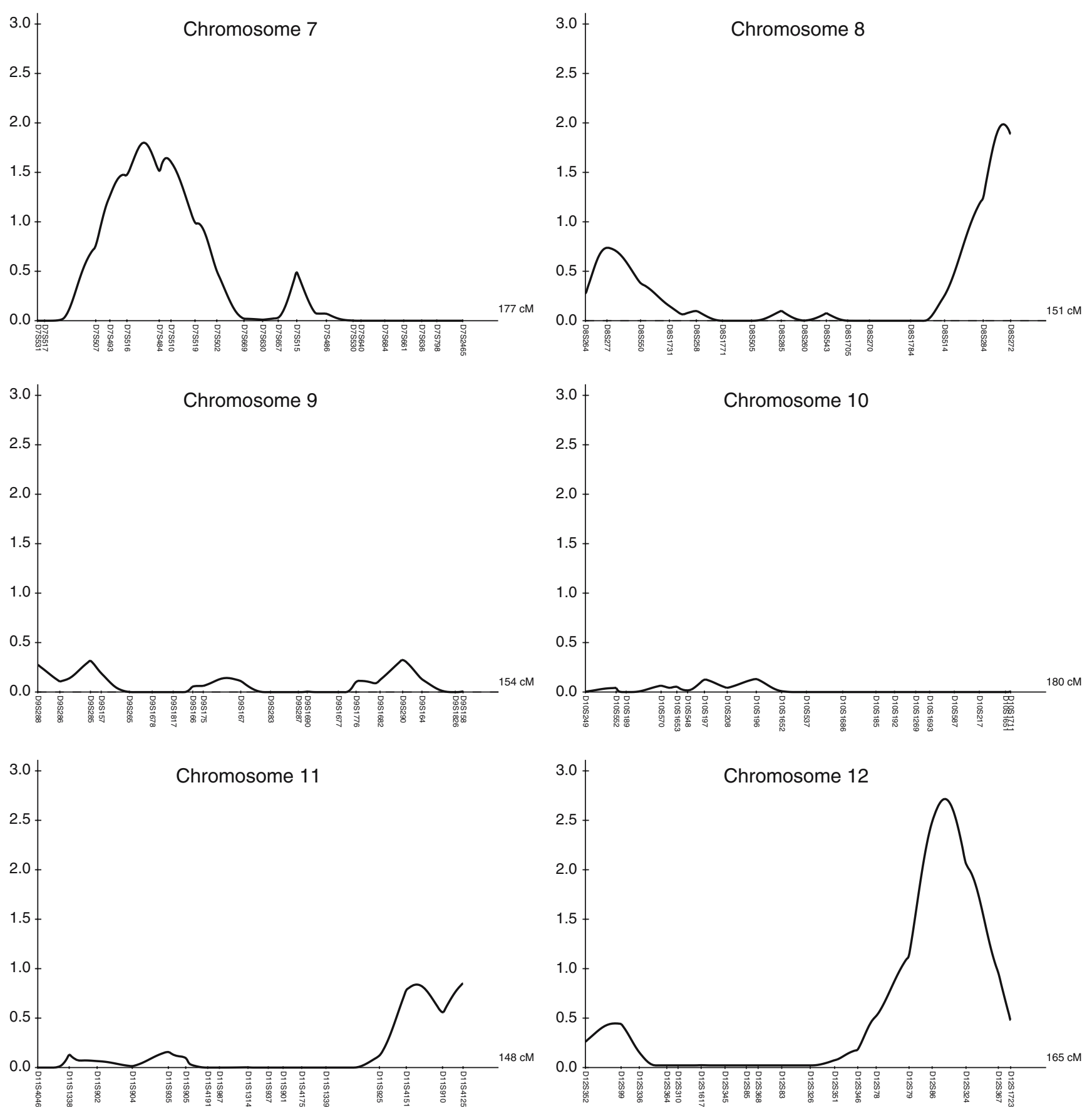

Fig. 2 continued

genotyping success rate was $98.4 \%$, and the overall average of information content was 0.70 .

The results of the genomewide linkage analysis are displayed in Fig. 2. Ten chromosomal regions, 4q35, 5q34, 6q27, 7p15, 8q24, 12q24, 18q23, 19q13, Xp22, and Xq27 showed maximum lod scores (MLS) greater than 1.0 (Fig. 2a-d; Table 4). Among them, the most significant region was 12q24 (MLS 2.69, NPL 2.64, $P=0.0043)$. The 1-lod support interval for this region spanned $25 \mathrm{cM}(129 \sim 154 \mathrm{cM})$. One hundred and twenty-eight genes are currently mapped within this interval (Table 5). Among them, 90 genes are believed to be expressed in organs related to immune function. Replacement and addition of markers around the peak of chromosome 12 increased information content from 0.66 to 0.84 . In this condition, MLS of the locus was 2.26 and was still above the threshold of suggestive linkage (Fig. 3). 

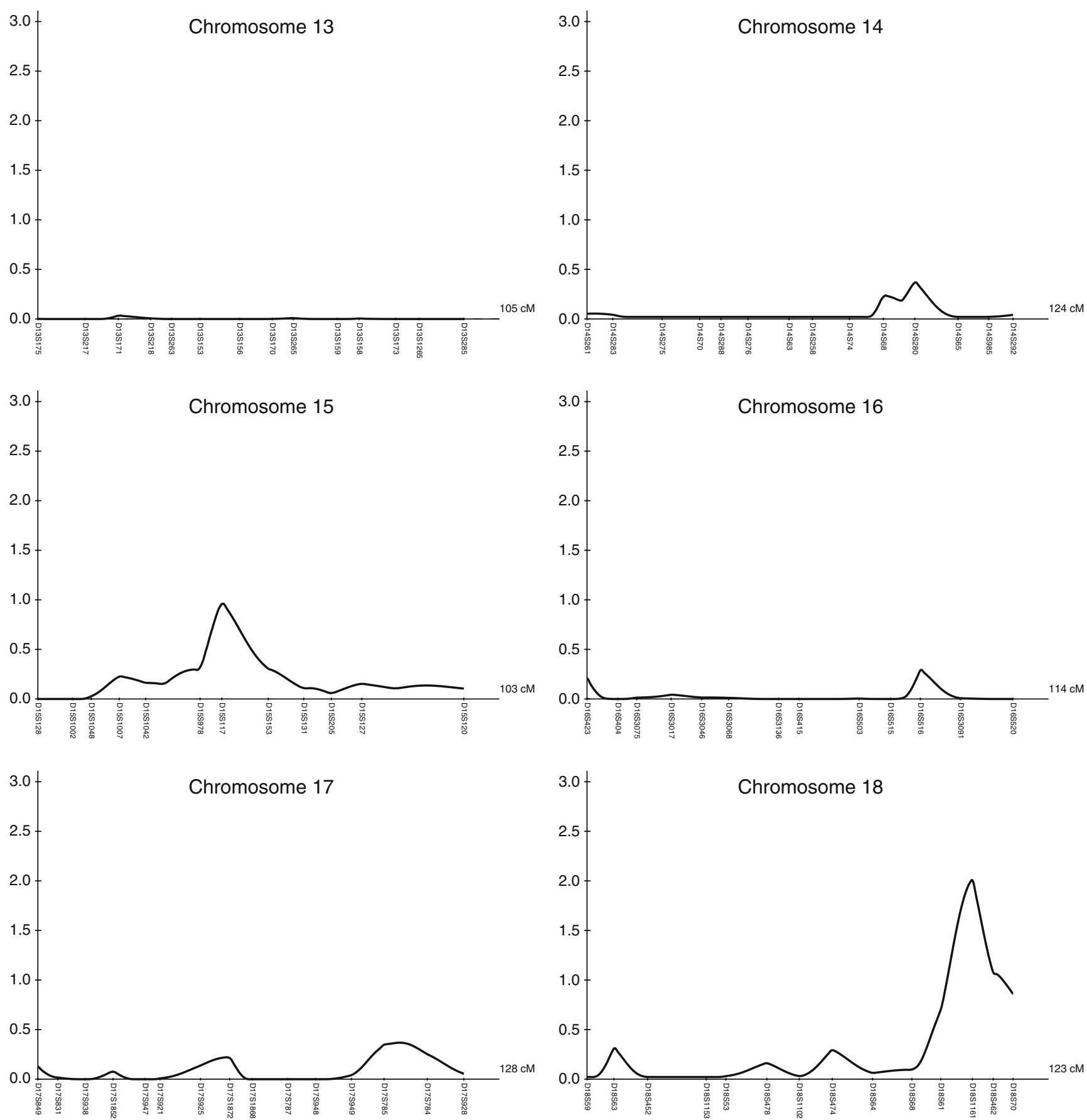

Fig. 2 continued

\section{Discussion}

$\mathrm{KD}$ is basically a self-limiting febrile illness that mainly affects infants and children. The most plausible trigger of $\mathrm{KD}$, as determined from clinical features, epidemiologic profiles, and laboratory findings, would be some unknown infection(s). Several candidate infectious agents have been isolated from specimens of KD patients in the acute phase (Tsurumizu et al. 1991;
Leung et al. 1993), but to date, no agents have been confirmed by the subsequent studies.

Since 1967, when KD was first reported by Kawasaki in Japan (Kawasaki 1967), much effort has been directed toward clarification of the pathogenesis and pathophysiology of the disease, but no therapeutic or preventive strategy based on etiological evidence has been developed. On the other hand, epidemiologic studies have shed light on the genetic aspects of KD as 

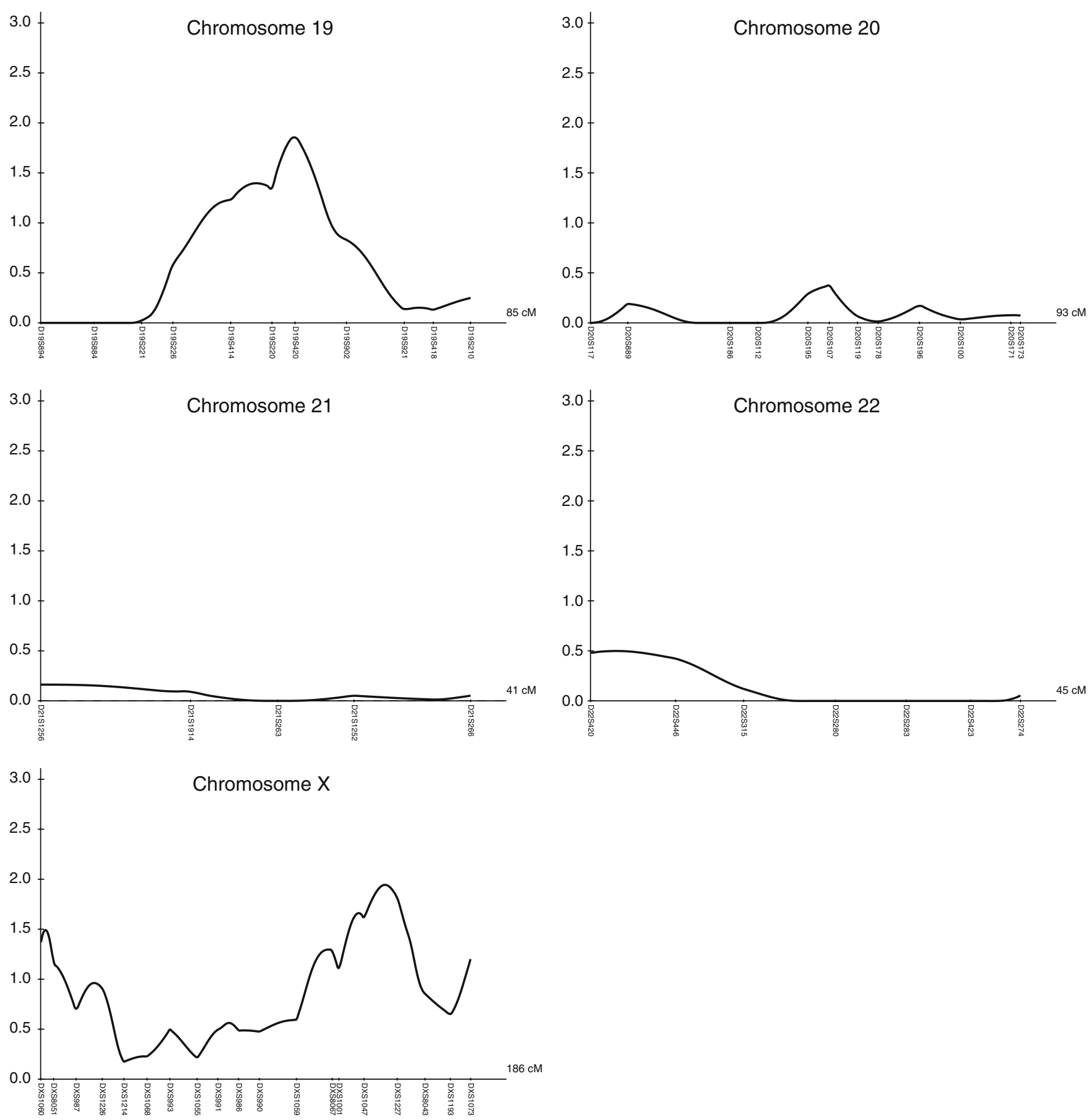

Fig. 2 continued

a result of two findings. One is an ethnic difference in disease prevalence: in Hawaii, increased prevalence in the Japanese American population has been observed (Dean et al. 1982). The other is familial aggregation of the disease: the relative risk of siblings $(\lambda \mathrm{s})$ for $\mathrm{KD}$ is about ten, and two-generation KD patients have been observed more frequently than expected (Fujita et al. 1989; Uehara et al. 2003). These findings clearly indicate the existence of some genetic factor(s) responsible for susceptibility to the disease. However, no multigenerational family suggesting a distinct inheritance pattern has been reported during the almost 40 years since KD was identified. Hence, we employed an NPL method in this study. As shown in Table 3, the observed linkage peaks were almost concordant using the two analysis methods. However, we considered that the utmost care was needed in the interpretation of NPL scores in this study. In contrast to the affected sib pair 
Table 4 Chromosomal regions with multipoint maximum likelihood scores $>1$

\begin{tabular}{|c|c|c|c|c|c|c|c|c|}
\hline Chromosome & $\begin{array}{l}\text { Position } \\
(\mathrm{cM})^{\mathrm{a}}\end{array}$ & $\begin{array}{l}\text { Position } \\
(\mathrm{Mb})\end{array}$ & $\begin{array}{l}\text { Multipoint } \\
\text { MLS }\end{array}$ & $\begin{array}{l}\text { Corresponding } \\
\text { markers }\end{array}$ & $\begin{array}{l}\text { Two-point } \\
\text { MLS }\end{array}$ & NPL score & $P$ value & $\begin{array}{l}\text { Position } \\
(\mathrm{cM})^{\mathrm{b}}\end{array}$ \\
\hline 4 & 195.7 & 184.9 & 1.30 & D4S1535 & 1.75 & 1.92 & 0.026 & 185.0 \\
\hline 5 & 152.6 & 149.6 & 1.14 & D5S640 & 0.76 & 1.64 & 0.054 & 148.7 \\
\hline 6 & 197.7 & 169.9 & 1.49 & D6S281 & 1.15 & 1.98 & 0.026 & 201.1 \\
\hline 7 & 48.8 & 30.1 & 1.80 & D7S510 & 1.54 & 2.47 & 0.0075 & 60.5 \\
\hline 8 & 149.7 & 135.7 & 1.99 & D8S272 & 1.39 & 1.85 & 0.034 & 152.5 \\
\hline 12 & 140.0 & 120.6 & 2.69 & D12S86 & 1.57 & 2.64 & 0.0043 & 135.1 \\
\hline 18 & 112.1 & 70.4 & 1.99 & D18S1161 & 1.49 & 2.12 & 0.018 & 112.0 \\
\hline 19 & 65.4 & 47.9 & 1.86 & D19S420 & 1.37 & 1.70 & 0.042 & 66.0 \\
\hline $\mathrm{X}$ & 12.1 & 7.0 & 1.49 & DXS1060 & 0.96 & $-^{\mathrm{c}}$ & $-^{\mathrm{c}}$ & $-^{\mathrm{c}}$ \\
\hline $\mathrm{X}$ & 159.1 & 139.3 & 1.94 & DXS1227 & 1.57 & 1.47 & 0.075 & 164.7 \\
\hline
\end{tabular}

${ }^{a}$ Genetic position of loci where maximum lod score (MLS) peaks were observed

${ }^{\mathrm{b}}$ Genetic position of loci where nonparametric linkage (NPL) peaks were observed

${ }^{c}$ No NPL peak was observed

analysis, the affection status of all relatives analyzed is reflected in the NPL score. Although correct information from the parents of their history of KD in childhood is essential, no such record was available. Thus, it is possible that unrecognized patients exist in the parents and the NPL score was underestimated.

The strongest evidence of linkage was observed in the $12 \mathrm{q} 24$ region $\quad(\mathrm{MLS}=2.69, \quad \mathrm{NPL}=2.64$, $P=0.0043)$. The level of likelihood of the region surpassed the threshold of suggestive linkage for genomewide sib pair analysis of complex trait $(\operatorname{lod}=2.2)$ (Lander and Kruglyak 1995). To achieve precise calculation of shared alleles identical by descent (IBD) in sib pair analysis, both collection of as many parents' samples as possible and usage of highly informative markers are important. In this study, we obtained samples of at least one parent from 48 pedigrees. In addition, the information content of the linkage peak on 12q24 was improved by addition and replacement of the markers.

Interestingly, positive linkage results have been reported in several studies on allergic disorders on the very same chromosomal region (Shao et al. 2004; Yokouchi et al. 2002; CSGA 1997). Together with the fact that children with KD history are at higher risk for allergy (Matsubara et al. 1998), it is plausible that the responsible gene(s) exists in this loci. As demonstrated in Table 5, more than a hundred known and predicted genes are located in the 1-lod support interval in this region. We are now searching for the gene variation for KD susceptibility by use of gene expression and linkage disequilibrium data available from public databases.

In terms of KD susceptibility, a significant association between a single nucleotide polymorphisms (SNP) in the $I L-4$ gene and KD was reported by Burns et al.
(2005). $I L-4$ is known to be located in the $5 \mathrm{q} 31.1$ region, where the so-called cytokine gene cluster exists. Several diseases related to autoimmunity or allergy have already been mapped to this region (Rioux et al. 2001; Palmer et al. 2001). In this study, although not significant, nominal evidence of linkage was observed in the region (MLS $=0.98$, data not shown). $I L-12 B$, located on $5 \mathrm{q} 33.3$ region, is one of the most-studied genes as candidates for immune-mediated diseases. In our study, another linkage peak was observed in the 5q33-34 region (Table 3). It is possible that variation of the genes associated with such disorders is associated with marked activation of the immune system in acutephase KD.

Another chromosomal region that has frequently been investigated in relation to immune disorders is $6 \mathrm{p} 21$, where human leukocyte antigen (HLA) genes are located. The association between HLA and development of KD remains controversial (Barron et al. 1992; Fildes et al. 1992; Kaslow et al. 1985; Krensky et al. 1981, 1983; Matsuda et al. 1977). No evidence of linkage was observed in the 6p21 region in the present study, which might indicate that HLA does not play a major role in terms of KD susceptibility.

Development of a prior prediction method of disease severity and outcome for individual KD patients in the acute phase would be a significant contribution to clinical practice. Responsiveness to immunoglobulin therapy and/or vascular wall fragility to immune insults could be also determined by genetic factors that could predict disease outcome, if clarified. Applying a positional candidate gene approach to the preliminary results of this linkage study, we have already identified an SNP within the CD40 ligand gene on chromosome $\mathrm{X}$ that is associated with coronary artery lesions in 
Table 5 Genes loacted within 1-lod confidence interval of linkage position on chromosome 12

\begin{tabular}{|c|c|c|c|c|c|}
\hline Start $^{\mathrm{a}}$ & End $^{\mathrm{a}}$ & Symbol & Orientation $^{\mathrm{b}}$ & Description & Expression $^{\mathrm{c}}$ \\
\hline 116065968 & 116112683 & FBXO21 & - & F-box protein 21 & + \\
\hline 116135362 & 116283965 & NOS1 & - & Nitric oxide synthase 1 (neuronal) & - \\
\hline 116389387 & 116777724 & KSR2 & - & Kinase suppressor of ras 2 & $\mathrm{NA}^{\mathrm{d}}$ \\
\hline 116938893 & 116954422 & RFC5 & + & Replication factor C (activator 1) $5,36.5 \mathrm{kDa}$ & + \\
\hline 116954875 & 116983334 & WSB2 & - & WD repeat and SOCS box-containing 2 & + \\
\hline 116987864 & 117034763 & FLJ20674 & - & Hypothetical protein FLJ20674 & + \\
\hline 117025878 & 117026516 & LOC653276 & - & Similar to hypothetical protein FLJ20674 & NA \\
\hline 117058253 & 117067773 & PEBP1 & + & Phosphatidylethanolamine binding protein 1 & + \\
\hline 117071989 & 117294934 & TAOK3 & - & TAO kinase 3 & + \\
\hline 117293767 & 117294150 & LOC728359 & + & Hypothetical protein LOC728359 & NA \\
\hline 117294521 & 117295201 & LOC728363 & + & Hypothetical protein LOC728363 & NA \\
\hline 117298741 & 117340223 & SUDS3 & + & $\begin{array}{l}\text { Suppressor of defective silencing } 3 \text { homolog (Saccharomyces } \\
\text { cerevisiae) }\end{array}$ & + \\
\hline 117903779 & 118085240 & KIAA1853 & + & KIAA1853 & - \\
\hline 118100978 & 118116934 & HSPB8 & + & Heat shock $22 \mathrm{kDa}$ protein 8 & + \\
\hline 118117019 & 118118290 & LOC643737 & + & $\begin{array}{l}\text { Similar to } 28 \mathrm{kDa} \text { heat- and acid-stable phosphoprotein } \\
\text { (PDGF-associated protein) (PAP) (PDGFA-associated protein 1) } \\
\text { (PAP1) }\end{array}$ & NA \\
\hline 118256900 & 118463235 & CCDC60 & + & Coiled-coil domain containing 60 & - \\
\hline 118515614 & 118563001 & LOC387890 & + & Similar to tumor suppressor candidate 5 & NA \\
\hline 118590144 & 118603812 & PRKAB1 & + & Protein kinase, AMP-activated, beta 1 non-catalytic subunit & + \\
\hline 118607981 & 118799475 & CIT & - & Citron (rho-interacting, serine/threonine kinase 21 ) & + \\
\hline 118912031 & 119016680 & CCDC64 & + & Coiled-coil domain containing 64 & + \\
\hline 119017286 & 119038982 & RAB35 & - & RAB35, member RAS oncogene family & + \\
\hline 119049397 & 119116896 & GCN1L1 & - & GCN1 general control of amino-acid synthesis 1-like 1 (yeast) & + \\
\hline 119118886 & 119123397 & RPLP0 & - & Ribosomal protein, large, $\mathrm{P} 0$ & + \\
\hline 119132640 & 119187892 & PXN & - & Paxillin & + \\
\hline 119140500 & 119143144 & LOC728803 & - & Similar to paxillin & NA \\
\hline 119204323 & 119205015 & NME2P1 & + & $\begin{array}{l}\text { Nonmetastatic cells } 2 \text {, protein (NM23B) expressed in, } \\
\text { pseudogene } 1\end{array}$ & NA \\
\hline 119213946 & 119214089 & RNU4B1 & - & RNA, U4B1 small nuclear & NA \\
\hline 119224546 & 119235428 & SIRT4 & + & $\begin{array}{l}\text { Sirtuin (silent mating type information regulation } 2 \text { homolog) } 4 \\
\quad(\text { S. cerevisiae })\end{array}$ & - \\
\hline 119244297 & 119249975 & PLA2G1B & - & Phospholipase A2, group IB (pancreas) & - \\
\hline 119263516 & 119291341 & MSI1 & - & Musashi homolog 1 (Drosophila) & - \\
\hline 119360287 & 119362915 & COX6A1 & + & Cytochrome c oxidase subunit VIa polypeptide 1 & + \\
\hline 119366147 & 119368598 & TRIAP1 & - & TP53 regulated inhibitor of apoptosis 1 & + \\
\hline 119368667 & 119382145 & 15E1.2 & + & Hypothetical protein LOC283459 & + \\
\hline 119383854 & 119391941 & SFRS9 & - & Splicing factor, arginine/serine-rich 9 & + \\
\hline 119392043 & 119420681 & DYNLL1 & + & Dynein, light chain, LC8-type 1 & + \\
\hline 119425467 & 119451336 & COQ5 & - & Coenzyme Q5 homolog, methyltransferase (S. cerevisiae) & + \\
\hline 119456538 & 119499740 & RNF10 & + & Ring finger protein 10 & + \\
\hline 119501231 & 119503584 & POP5 & - & $\begin{array}{l}\text { Processing of precursor 5, ribonuclease P/MRP subunit } \\
\quad(\text { S. cerevisiae })\end{array}$ & + \\
\hline 119516198 & 119516734 & LOC643499 & - & Similar to 60 S ribosomal protein L11 & NA \\
\hline 119562805 & 119589510 & CABP1 & + & Calcium binding protein 1 (calbrain) & - \\
\hline 119609332 & 119624050 & KIAA0152 & + & KIAA0152 & + \\
\hline 119632214 & 119645826 & MGC5139 & + & Hypothetical protein MGC5139 & + \\
\hline 119648050 & 119662193 & ACADS & + & Acyl-coenzyme A dehydrogenase, C-2 to C-3 short chain & + \\
\hline 119685418 & 119826534 & SPPL3 & - & Signal peptide peptidase 3 & + \\
\hline 119826639 & 119837312 & LOC390363 & + & Similar to chloride intracellular channel 1 & NA \\
\hline 119837402 & 119839284 & LOC643550 & + & Similar to 60 S ribosomal protein L12 & NA \\
\hline 119900932 & 119924698 & TCF1 & + & $\begin{array}{l}\text { Transcription factor 1, hepatic; LF-B1, hepatic nuclear factor } \\
\text { (HNF1), albumin proximal factor }\end{array}$ & + \\
\hline 119925231 & 119938683 & C12orf43 & - & Chromosome 12 open reading frame 43 & + \\
\hline 119942478 & 119961163 & OASL & - & $2^{\prime}-5^{\prime}$-oligoadenylate synthetase-like & + \\
\hline 120029367 & 120029654 & LOC390364 & + & Similar to ribosomal protein L10 & NA \\
\hline 120055061 & 120108259 & $\mathrm{P} 2 \mathrm{RX} 7$ & + & Purinergic receptor $\mathrm{P} 2 \mathrm{X}$, ligand-gated ion channel, 7 & + \\
\hline 120132047 & 120156292 & $\mathrm{P} 2 \mathrm{RX} 4$ & + & Purinergic receptor $\mathrm{P} 2 \mathrm{X}$, ligand-gated ion channel, 4 & + \\
\hline 120159878 & 120220494 & CAMKK2 & - & Calcium/calmodulin-dependent protein kinase kinase 2 , beta & + \\
\hline 120230543 & 120274585 & ANAPC5 & - & Anaphase promoting complex subunit 5 & + \\
\hline 120322285 & 120346538 & RNF34 & + & Ring finger protein 34 & + \\
\hline 120351282 & 120503272 & FBXL10 & - & F-box and leucine-rich repeat protein 10 & + \\
\hline 120548858 & 120564322 & TMEM142A & + & Transmembrane protein $142 \mathrm{~A}$ & + \\
\hline 120573676 & 120591943 & MORN3 & - & MORN repeat containing 3 & + \\
\hline
\end{tabular}


Table 5 Continued

\begin{tabular}{|c|c|c|c|c|c|}
\hline Start $^{\mathrm{a}}$ & End $^{\mathrm{a}}$ & Symbol & Orientation $^{\mathrm{b}}$ & Description & Expression $^{\mathrm{c}}$ \\
\hline 120700043 & 120715977 & RHOF & - & Ras homolog gene family, member F (in filopodia) & + \\
\hline 120717566 & 120720119 & LOC338799 & - & Hypothetical locus LOC338799 & + \\
\hline 120726308 & 120754945 & SETD1B & + & SET domain containing $1 \mathrm{~B}$ & + \\
\hline 120761816 & 120781152 & HPD & - & 4-Hydroxyphenylpyruvate dioxygenase & - \\
\hline 120811029 & 120840154 & PSMD9 & + & Proteasome (prosome, macropain) 26S subunit, non-ATPase, 9 & + \\
\hline 120840866 & 120926203 & WDR66 & + & WD repeat domain 66 & + \\
\hline 120944244 & 120984333 & BCL7A & + & B-cell CLL/lymphoma 7A & + \\
\hline 121001143 & 121001559 & LOC728551 & + & Similar to mondoA & NA \\
\hline 121177744 & 121192312 & MLXIP & + & MLX interacting protein & + \\
\hline 121218219 & 121253970 & LRRC43 & + & Leucine rich repeat containing 43 & + \\
\hline 121222530 & 121224699 & IL31 & - & Interleukin 31 & + \\
\hline 121254181 & 121258037 & B3GNT4 & + & UDP-GlcNAc:betaGal beta-1,3- $N$-acetylglucosaminyltransferase 4 & + \\
\hline 121258162 & 121276552 & DIABLO & - & Diablo homolog (Drosophila) & + \\
\hline 121282047 & 121317021 & VPS33A & - & Vacuolar protein sorting 33 homolog A (S. cerevisiae) & + \\
\hline 121321934 & 121473069 & $\mathrm{RSN}$ & - & $\begin{array}{l}\text { Restin (Reed-Steinberg cell-expressed intermediate filament- } \\
\text { associated protein) }\end{array}$ & + \\
\hline 121415246 & 121416199 & RPL21P1 & + & Ribosomal protein L21 pseudogene 1 & NA \\
\hline 121472222 & 121473785 & LOC728569 & + & Hypothetical protein LOC728569 & NA \\
\hline 121523388 & 121551471 & ZCCHC8 & - & Zinc finger, $\mathrm{CCHC}$ domain containing 8 & + \\
\hline 121555226 & 121577500 & FLJ11021 & - & Similar to splicing factor, arginine/serine-rich 4 & + \\
\hline 121577762 & 121676900 & KNTC1 & + & Kinetochore associated 1 & + \\
\hline 121751793 & 121753857 & GPR109A & - & G protein-coupled receptor $109 \mathrm{~A}$ & + \\
\hline 121765256 & 121767297 & GPR109B & - & G protein-coupled receptor $109 \mathrm{~B}$ & + \\
\hline 121778106 & 121781082 & GPR81 & - & G protein-coupled receptor 81 & + \\
\hline 121803324 & 121821906 & DENR & + & Density-regulated protein & + \\
\hline 121825026 & 121877884 & CCDC62 & + & Coiled-coil domain containing 62 & + \\
\hline 121885992 & 121913460 & HIP1R & + & Huntingtin interacting protein 1 related & + \\
\hline 121912215 & 121913461 & LOC728014 & + & Similar to huntingtin interacting protein 1 related & NA \\
\hline 121915835 & 121946665 & VPS37B & - & Vacuolar protein sorting 37 homolog B (S. cerevisiae) & + \\
\hline 121979492 & 122025705 & ABCB 9 & - & ATP-binding cassette, subfamily B (MDR/TAP), member 9 & + \\
\hline 122025307 & 122030541 & OGFOD2 & + & $\begin{array}{l}\text { 2-Oxoglutarate and iron-dependent oxygenase domain } \\
\text { containing } 2\end{array}$ & + \\
\hline 122030833 & 122033413 & ARL6IP4 & + & ADP-ribosylation-like factor 6 interacting protein 4 & + \\
\hline 122033980 & 122160928 & PITPNM2 & - & Phosphatidylinositol transfer protein, membrane-associated 2 & + \\
\hline 122199995 & 122202729 & LOC728604 & + & Hypothetical protein LOC728604 & NA \\
\hline 122206899 & 122272394 & MPHOSPH9 & - & M-phase phosphoprotein 9 & + \\
\hline 122283416 & 122308459 & FLJ38663 & + & Hypothetical protein FLJ38663 & + \\
\hline 122311491 & 122322640 & CDK2AP1 & - & CDK2-associated protein 1 & + \\
\hline 122346408 & 122400941 & SBNO1 & - & Sno, strawberry notch homolog 1 (Drosophila) & + \\
\hline 122414368 & 122416610 & LOC728046 & - & Similar to sno, strawberry notch homolog 1 (Drosophila) & NA \\
\hline 122434657 & 122459853 & SETD8 & + & SET domain containing (lysine methyltransferase) 8 & + \\
\hline 122464088 & 122466421 & LOC728069 & + & Similar to T-box 1 isoform $\mathrm{C}$ & NA \\
\hline 122465889 & 122487217 & MGC7036 & - & hypothetical protein MGC7036 & + \\
\hline 122508604 & 122516894 & U1SNRNPBP & + & U11/U12 snRNP 35K & + \\
\hline 122522316 & 122584453 & FLJ39378 & - & Hypothetical protein FLJ39378 & + \\
\hline 122584314 & 122584955 & LOC728618 & - & Hypothetical protein LOC728618 & - \\
\hline 122635114 & 122648639 & TMED2 & + & Transmembrane emp24 domain trafficking protein 2 & + \\
\hline 122652625 & 122671435 & DDX55 & + & DEAD (Asp-Glu-Ala-Asp) box polypeptide 55 & + \\
\hline 122671523 & 122684200 & EIF2B1 & - & Eukaryotic translation initiation factor $2 \mathrm{~B}$, subunit 1 alpha, $26 \mathrm{kDa}$ & + \\
\hline 122684334 & 122711287 & GTF2H3 & + & General transcription factor IIH, polypeptide $3,34 \mathrm{kDa}$ & + \\
\hline 122721644 & 122758901 & C12orf38 & + & Chromosome 12 open reading frame 38 & + \\
\hline 122762818 & 122810394 & ATP6V0A2 & + & ATPase, $\mathrm{H}+$ transporting, lysosomal V0 subunit a2 & + \\
\hline 122831604 & 122864757 & DNAH10 & + & Dynein, axonemal, heavy polypeptide 10 & + \\
\hline 122986908 & 123023116 & CCDC92 & - & Coiled-coil domain containing 92 & + \\
\hline 123023623 & 123065922 & ZNF664 & + & Zinc finger protein 664 & + \\
\hline 123339663 & 123366521 & FAM101A & + & Family with sequence similarity 101 , member A & - \\
\hline 123374914 & 123568793 & NCOR2 & - & Nuclear receptor co-repressor 2 & + \\
\hline 123828129 & 123914287 & SCARB1 & - & Scavenger receptor class $\mathrm{B}$, member 1 & + \\
\hline 123962145 & 123965360 & UBC & - & Ubiquitin $\mathrm{C}$ & + \\
\hline 123985979 & 123986364 & LOC644022 & - & Hypothetical protein LOC644022 & NA \\
\hline 123997325 & 124039620 & DHX37 & - & DEAH (Asp-Glu-Ala-His) box polypeptide 37 & + \\
\hline 124044147 & 124076302 & BRI3BP & + & BRI3 binding protein & + \\
\hline 124115960 & 124193819 & AACS & + & Acetoacetyl-CoA synthetase & + \\
\hline 124237299 & 124238021 & LOC728696 & + & Hypothetical protein LOC728696 & - \\
\hline 124377115 & 124709542 & TMEM132B & + & Transmembrane protein 132B & + \\
\hline
\end{tabular}


Table 5 Continued

\begin{tabular}{llllll}
\hline Start $^{\mathrm{a}}$ & End $^{\mathrm{a}}$ & Symbol & Orientation $^{\mathrm{b}}$ & Description & Expression $^{\mathrm{c}}$ \\
\hline 124735720 & 124736028 & LOC644152 & - & Similar to CG32774-PA & NA \\
125218734 & 125222165 & LOC728171 & + & Hypothetical protein LOC728171 & - \\
125476645 & 125484720 & LOC728173 & + & Hypothetical protein LOC728173 & NA \\
125560617 & 125561774 & PGBD3P3 & + & PiggyBac transposable element derived 3 pseudogene 3 & NA \\
125780624 & 125822726 & LOC387895 & - & Hypothetical gene supported by BC040060 & + \\
125914962 & 125927273 & LOC121296 & + & Hypothetical LOC121296 & NA \\
126681767 & 126686506 & LOC644489 & - & Hypothetical protein LOC644489 & NA \\
\hline
\end{tabular}

a Annotation was done according to the recent National Center for Biotechnology Information (NCBI) build 36.2 chromosome 12 sequence

b Genes transcribed in the orientation from $p$ ter to $q$ ter are represented by '+', and vice versa

c Information of gene expression in immune-related organs (blood, bone marrow, lymph node, lymphocyte, tonsil, spleen, and thymus) was obtained from the web site of UniGene EST Profile Viewer. (http://www.ncbi.nlm.nih.gov/entrez/query.fcgi?db=unigene)

${ }^{\mathrm{d}}$ No data was available

male KD patients (Onouchi et al. 2004). Although only a few concordant sib pair cases of coronary artery lesions were involved in the present study, other linkage

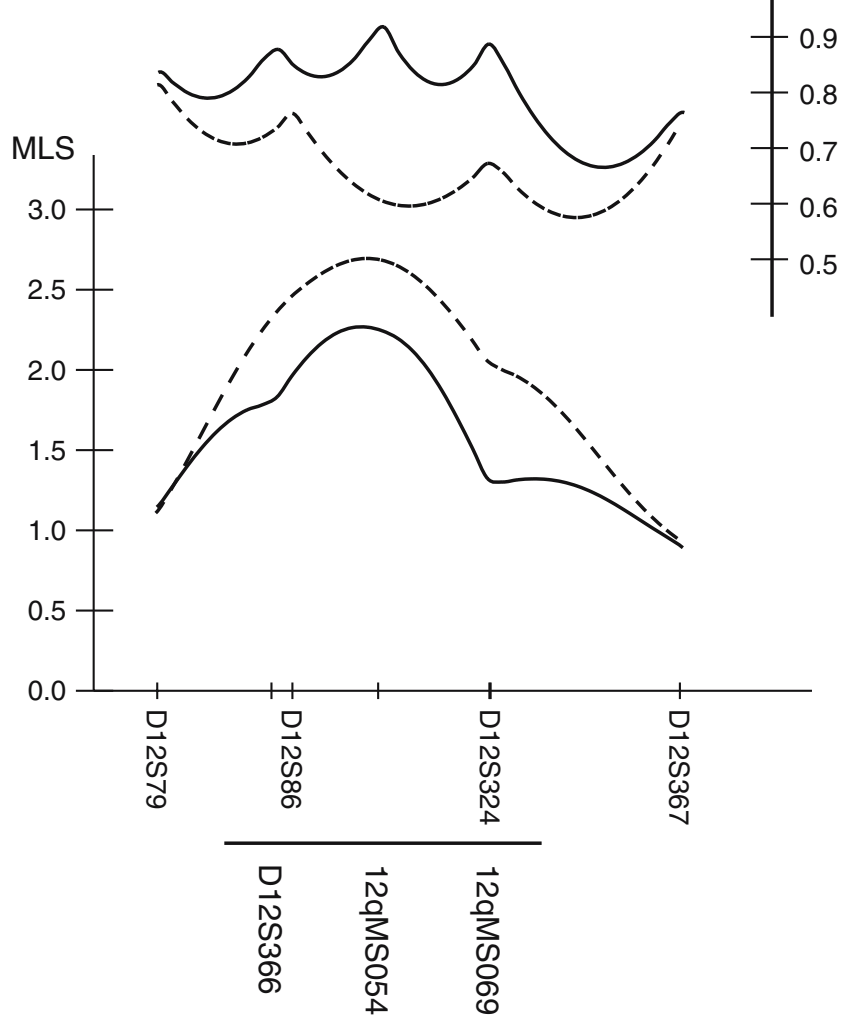

Fig. 3 Information content and lod score with alternative marker set in $12 \mathrm{q}$ region. Markers of the first row are the set used in the initial scan. Replaced or added markers are in the second row. Plots for information content (IC) and maximum lod score (MLS) are drawn on the upper and lower part of the chart, respectively. Broken and continuous lines indicate the results in the initial scan and alternative high information scan, respectively peaks observed may also represent loci for susceptibility to cardiac complication.

The present study has revealed ten regions potentially involved in KD susceptibility. This is the first genome-wide genetic analysis for KD. Our findings will facilitate identification of genetic variations associated with KD susceptibility. The accumulation of knowledge on genetic factors should clarify etiology and pathogenesis of the disease and lead to the development of effective therapeutic measures.

Acknowledgments We thank patients and their families for participating in the project. We are grateful to Dr. Etsuko Tsuda, Dr. Shigeo Kojima, Dr. Marina Takenaka, Dr. Yutaka Izumi, Dr. Zenshiro Onouchi, Dr. Kaname Koyama, Dr. Atushi Ono, Dr. Fumie Furukawa, Dr. Takuji Otsuka, Dr. Takashi Hashimoto, Dr. Reiko Yabuta, Dr. Hirotoshi Iwahori, Dr. Yujiro Kimura, Dr. Yuji Murata, Dr. Ken Suzaki, Dr. Ken Takagawa, Dr. Michindo Ninomiya, Dr. Yukinobu Shibata, Dr. Minoru Kubo, Dr. Yuriko Sekine, Dr. Eikan Koh, Dr. Takeshi Terao, Dr. Mayumi Sugimori, Dr. Takashi Soga, Dr. Shigeki Terada, Dr. Nobuyuki Kiyosawa, Dr. Kunihiro Hamamoto, Dr. Noriko Baba, Dr. Hideo, Yamaguchi, Dr. Tatsuo Handa, Dr. Masashi Shiomi, Dr., Kensuke Harada, Dr. Yoshiyasu Yamada, Dr. Kazue IInuma, Dr. Sumio Hyodo, Dr. Masaru Miura, Dr. Haruo Terada, Dr. Mayumi Onda, Dr. Yoshiharu Suzuki, Dr. Shiro Tsuchiya, Dr. Naoto Tanaka, Dr. Masaki Nakagawa, Dr. Kisei Minami, Dr. Atsushi Toyoda, Dr. Chieko Udo, Dr. Kenji Yabuta, Dr. Tomio Kobayashi, Dr. Akira Kohno, Dr. Masumi Koujiro, Dr. Yasuhiko Tonegawa, Dr. Yuji Sakakura, Dr. Yutaka Yamada, Dr. Masanobu Ito, Dr. Fumiko Baba, Dr. Junji Suga, Dr. Kiyotaka Usui, Dr. Takashi Kawamura, Dr. Katsumi Takei, Dr. Seiji Noma, Dr. Mamie Watanabe, Kazunobu Ouchi, Dr. Tsutomu Saji, Dr. Tsuyoshi Isobe, and all their colleagues for cooperating in sample collection. The authors declare that they have no competing financial interests.

\section{References}

Barron KS, Silverman ED, Gonzales JC, St Clair M, Anderson K, Reveille JD (1992) Major histocompatibility complex class II alleles in Kawasaki syndrome-lack of consistent 
correlation with disease or cardiac involvement. J Rheumatol 19:1790-1793

Burns JC (2002) Commentary: translation of Dr. Tomisaku Kawasaki's original report of fifty patients in 1967. Pediatr Infect Dis J 21:993-995

Burns JC, Shimizu C, Shike H, Newburger JW, Sundel RP, Baker AL, Matsubara T, Ishikawa Y, Brophy VA, Cheng S, Grow MA, Steiner LL, Kono N, Cantor RM. (2005) Familybased association analysis implicates IL-4 in susceptibility to Kawasaki disease. Genes Immun 6:438-444

Dean AG., Melish ME, Hicks R, Palumbo NE (1982) An epidemic of Kawasaki syndrome in Hawaii. J Pediatr 100:552-557

Fildes N, Burns JC, Newburger JW, Klitz W, Begovich AB (1992) The HLA class II region and susceptibility to Kawasaki disease. Tissue Antigens 39:99-101

Fujita Y, Nakamura Y, Sakata K, Hara N, Kobayashi M, Nagai M, Yanagawa H, Kawasaki T (1989) Kawasaki disease in families. Pediatrics 84:666-669

Ikari K, Onda H, Furushima K, Maeda S, Harata S, Takeda J (2001) Establishment of an optimized set of 406 microsatellite markers covering the whole genome for the Japanese population. J Hum Genet 46:207-210

Kaslow RA, Bailowitz A, Lin FY, Koslowe P, Simonis T, Israel E (1985) Association of epidemic Kawasaki syndrome with the HLA-A2, B44, Cw5 antigen combination. Arthritis Rheum 28:938-940

Kato H, Koike S, Yamamoto M, Ito Y, Yano E (1975) Coronary aneurysms in infants and young children with acute febrile mucocutaneous lymph node syndrome. J Pediatr 86:892-898

Kato H, Sugimura T, Akagi T, Sato N, Hashino K, Maeno Y, Kazue T, Eto G, Yamakawa R (1996) Long-term consequences of Kawasaki disease. A 10- to 21-year follow-up study of 594 patients. Circulation 94:1379-1385

Kawasaki T (1967) Acute febrile mucocutaneous syndrome with lymphoid involvement with specific desquamation of the fingers and toes: my clinical observation (in Japanese). Jpn J Allergy 16:178-222

Krensky AM, Berenberg W, Shanley K, Yunis EJ (1981) HLA antigens in mucocutaneous lymph node syndrome in New England. Pediatrics 67:741-743

Krensky AM, Grady S, Shanley KM, Berenberg W, Yunis EJ (1983) Epidemic and endemic HLA-B and DR associations in mucocutaneous lymph node syndrome. Hum Immunol 6:75-77

Kruglyak L, Lander ES (1995) Complete multipoint sib-pair analysis of qualitative and quantitative traits. Am J Hum Genet 57:439-454

Kruglyak L, Daly MJ, Reeve-Daly MP, Lander ES (1996) Parametric and nonparametric linkage analysis: a unified multipoint approach. Am J Hum Genet 58:1347-1363

Lander E, Kruglyak L (1995) Genetic dissection of complex traits: guidelines for interpreting and reporting linkage results. Nat Genet 11:241-247

Leung DY, Meissner HC, Fulton DR, Murray DL, Kotzin BL, Schlievert PM (1993) Toxic shock syndrome toxin-secreting Staphylococcus aureus in Kawasaki syndrome. Lancet 342:1385-1388
Matsubara T, Fujita Y, Sato T, Sasai K, Furukawa S (1998) The prevalence of allergy in Kawasaki disease. Allergy 53:815816

Matsuda I, Hattori S, Nagata N, Fruse A, Nambu H (1977) HLA antigens in mucocutaneous lymph node syndrome. Am J Dis Child 131:1417-1418

Onouchi Y, Onoue S, Tamari M, Wakui K, Fukushima Y, Yashiro M, Nakamura Y, Yanagawa H, Kishi F, Ouchi K, Terai M, Hamamoto K, Kudo F, Aotsuka H, Sato Y, Nariai A, Kaburagi Y, Miura M, Saji T, Kawasaki T, Nakamura Y, Hata A (2004) CD40 ligand gene and Kawasaki disease. Eur J Hum Genet 12:1062-1068

Palmer LJ, Barnes KC, Burton PR, Chen H, Cookson WO, Collaborative Study on the Genetics of Asthma, Deichmann KA, Elston RC, Holloway JW, Jacobs KB, Laitinen T, Wjst M (2001) Meta-analysis for linkage to asthma and atopy in the chromosome 5q31-33 candidate region. Hum Mol Genet 10:891-899

Rioux JD, Daly MJ, Silverberg MS, Lindblad K, Steinhart H, Cohen Z, Delmonte T, Kocher K, Miller K, Guschwan S. Kulbokas EJ, O'Leary S, Winchester E, Dewar K, Green T, Stone V, Chow C, Cohen A, Langelier D, Lapointe G, Gaudet D, Faith J, Branco N, Bull SB, McLeod RS, Griffiths AM, Bitton A, Greenberg GR, Lander ES, Siminovitch KA, Hudson TJ (2001) Genetic variation in the $5 \mathrm{q} 31$ cytokine gene cluster confers susceptibility to Crohn disease. Nat Genet 29:223-228

Risch N (1990) Linkage strategies for genetically complex traits. II. The power of affected relative pairs. Am J Hum Genet 46:229-241

Shao C, Suzuki Y, Kamada F, Kanno K, Tamari M, Hasegawa K, Aoki Y, Kure S, Yang X, Endo H, Takayanagi R, Nakazawa C, Morikawa T, Morikawa M, Miyabayashi S, Chiba Y, Karahashi M, Saito S, Tamura G, Shirakawa T, Matsubara Y (2004) Linkage and association of childhood asthma with the chromosome 12 genes. J Hum Genet 49:115-122

The Collaborative Study on the Genetics of Asthma (CSGA) (1997) A genome-wide search for asthma susceptibility loci in ethnically diverse populations. Nat Genet 15:389-392

Tsurumizu T, Okonogi H, Shibusawa T, Hashimoto T, Makino M, Ota H, Kurosaki T, Toba T (1991) A case of Kawasaki's disease combined with septicemia-isolation of Streptococcus sanguis (MCLS-1) and Streptococcus pyogenes from blood at the acute stage. Kansenshogaku Zasshi (Jpn) 65:124-128

Uehara R, Yashiro M, Nakamura Y, Yanagawa H (2003) Kawasaki disease in parents and children. Acta Paediatr 92:694-697

Yanagawa H, Nakamura Y, Yashiro M, Ojima T, Tanihara S, Oki I, Zhang T (1998) Results of the nationwide epidemiologic survey of Kawasaki disease in 1995 and 1996 in Japan. Pediatrics 102:E65

Yokouchi Y, Shibasaki M, Noguchi E, Nakayama J, Ohtsuki T, Kamioka M, Yamakawa-Kobayashi K, Ito S, Takeda K, Ichikawa K, Nukaga Y, Matsui A, Hamaguchi H, Arinami T (2002) A genome-wide linkage analysis of orchard grasssensitive childhood seasonal allergic rhinitis in Japanese families. Genes Immun 3:9-13 